\title{
Postharvest Quality of Cut Zinnia Flowers Cultivated Under Different Irrigation Levels and Growing Seasons
}

\author{
Rosária da Costa Faria Martins (Corresponding author) \\ Dept. of Crop Science, Agronomy Institute, Federal Rural University of Rio de Janeiro \\ BR-465 Highway, km 07, Seropédica - RJ, 23897-000, Brazil \\ Tel: +55 21 99620-3384Ｅ-mail: rosaria.cfmartins@gmail.com \\ Rogério Gomes Pêgo
}

Dept. of Crop Science, Agronomy Institute, Federal Rural University of Rio de Janeiro BR-465 Highway, km 07, Seropédica - RJ, 23897-000, Brazil

E-mail: engagropego@yahoo.com.br

\author{
Eleandro Silva da Cruz \\ National Institute of Colonization and Agrarian Reform \\ Senador Robert Kennedy Ave., 601, Vila Velha - ES, 29114-300, Brazil \\ E-mail: elcruz79@gmail.com
}

Mateus Marques Bueno

Agronomy Institute, Federal Institute of Education, Science and Technology of Minas Gerais

Primeiro de Junho Ave., 1043, São João Evangelista - MG, 39705-000, Brazil

E-mail: mateusjuruaia@gmail.com

Daniel Fonseca de Carvalho

Dept. of Engineering, Technology Institute, Federal Rural University of Rio de Janeiro

BR-465 Highway, km 07, Seropédica - RJ, 23890-000, Brazil

E-mail: daniel.fonseca.carvalho@gmail.com 
MlMacrothink

Received: November 26, 2020

doi:10.5296/jas.v9i1.17996
Journal of Agricultural Studies

ISSN 2166-0379

2021, Vol. 9, No. 1

Accepted: January 3, 2021 Published: January 14, 2021

URL: https://doi.org/10.5296/jas.v9i1.17996

\begin{abstract}
The quality of floral stems depends on a set of pre-harvest factors which can influence their postharvest longevity. Although the identification of visual signs of senescence through scales is decisive in assessing the loss of floral quality in the postharvest period, this scale does not exist for zinnia flowers (Zinnia elegans Jacq.). Thus, the objectives of this study were to evaluate the effect of different irrigation levels and growing seasons on the postharvest longevity of zinnia floral stems; and to determine a senescence scale to assess their durability. Therefore, zinnia plants ( $c v$. "Red California Giant") were cultivated in pots inside a greenhouse in Seropédica (Rio de Janeiro, Brazil), with a randomized block design, under four irrigation levels $(46 \%, 64 \%, 75 \%$ and $100 \%$ of the species' water requirement) and two cycles (autumn-winter and winter-spring). At the end of each cycle, 48 stems from each treatment were harvested and placed in containers holding $300 \mathrm{~mL}$ of supply water. For all irrigation levels and crop cycles, there was an increase in the fresh stem weight on the first days after harvesting and the water absorption rate was higher on the first day of evaluation. The proposed senescence scale allowed us to evaluate the loss of floral quality in the postharvest period. The stems from both cycles had satisfactory results, mainly of commercial longevity and the score 5 on the scale, which represents $100 \%$ of the stems' market value. The main postharvest results of the zinnia floral stems were not influenced by the irrigation levels.
\end{abstract}

Keywords: Zinnia elegans Jacq., senescence scale, longevity, irrigation management, floriculture

\title{
1. Introduction
}

The floriculture and ornamental plants' sector in the Brazilian agribusiness is an economically growing activity that has a great potential for expansion (Junqueira \& Peetz, 2014). Throughout the world, floriculture contributes with a production value of about $€$ 37,000 million to the horticultural sector (Cassaniti et al., 2013). To increase this production value, it is necessary to use techniques that favor the development and the ultimate quality of the flowers.

Irrigation management is crucial to the productivity of this sector since deficient or excessive irrigation reduces productivity and the quality of flowers (Farias et al., 2009). Besides this, there is limited information about the effect of weather conditions on the quality of flowers. However, temperature and other environmental factors influence the final quality of the product (Ebrahimzadeh et al., 2008).

Pre-harvest factors that define the final product's quality include its genetic material, its adaptation to environmental conditions and cultivation techniques used (Lima \& Ferraz, 2008). Therefore, the obtaining of flowers of good quality results from a set of actions in the 
production system such as adequate management of the crop, use of skilled labor, harvest practices, packaging and the conditions of the postharvest period of the floral stems (Loges et al., 2005).

Postharvest operations are vital in preserving the quality of the product for as long as possible, reducing losses and increasing the producer's profitability. Therefore, interference in postharvest factors increases the longevity of the product but does not improve its quality (Lima \& Ferraz, 2008). However, pre-harvest factors can also affect the durability of flowers such as the average temperature of the day that has an impact on gerbera's longevity, a species of the Asteraceae family (Davarynejad et al., 2008).

To understand the postharvest conditions of cut flowers, the senescence symptoms and the longevity must be observed. These evaluations determine the limits among the harvest, packaging, transport and marketing of the stems, and in the producer's planning, who aims to sell the flowers on specific dates or holidays. It is important to identify the visual signs of senescence in ornamental plants, since the ornamental value is strongly determined by the aesthetic value, being visual scales often established to determine quality standards. The use of senescence scales reduces the subjectivity of longevity estimates, allowing the stems to be commercialized with higher quality (Curti et al., 2012). However, only flowers with more significant economic impact have these scales, such as rose (Almeida et al., 2009) and sunflower (Curti et al., 2012).

For zinnia (Zinnia elegans Jacq.), species of the Asteraceae family of great potential in Brazil that presents an immense diversity of colors and petal shapes (Franzen et al., 2016), there are few studies about the longevity and postharvest characteristics of its flowers. Parameters such as density, porosity and water retention capacity of the growth substrate are known to influence the initial development of zinnia, and its floral quality (Pêgo et al., 2019; Sardoei et al., 2014). As regards the influence of irrigation management, Heidari et al. (2016) illustrated that growing plants under low water availability in arid or semi-arid climates leads to a decrease in the postharvest durability of zinnia flowers, $c v$. "Dreamland Red. Nevertheless, to the best of our knowledge, there are no research studies that report the effects of the cultivation of zinnia in different climatic conditions on its postharvest longevity.

To address the limited information in the literature on the postharvest quality of zinnia and the effect of different management techniques in this process, this study evaluated the effect of different irrigation levels and growing seasons on the postharvest longevity of zinnia floral stems, $c v$. "Red California Giant", obtained from cultivations in a greenhouse. It was also developed a market-value senescence scale, to assess the durability of cut zinnia flowers.

\section{Method}

\subsection{Experimental Conditions and Experimental Design}

This study was conducted on harvested zinnia floral stems grown in a greenhouse in Seropédica (Rio de Janeiro, Brazil) between March and May of 2019 (autumn-winter, AW cycle) and between July and October of 2019 (winter-spring, WS cycle). 
At the time of transplanting, the zinnia seedlings, $c v$. "Red California Giant" (ISLA Seeds, Rio Grande do Sul, Brazil) had between two and three pairs of leaves. Three seedlings, in a triangle formation $15 \mathrm{~cm}$ apart, were transplanted into $8 \mathrm{~L}$ capacity pots filled with a substrate composed of equal parts of sandy clay soil and powdered coconut fiber by volume.

The experiments were carried out in a completely randomized block design and a factorial scheme 4x2 (four irrigation levels: very low, low, intermediate and well-irrigated and two crop cycles) arranged on split plots in time. The experimental area of each cycle was composed of six replications, corresponding to six blocks, totalizing 24 experimental plots (irrigation levels) with three pots each, which were $20 \mathrm{~cm}$ apart.

The different irrigation levels were automatically delivered using two sets of controllers (Medici et al., 2010) installed in the well-irrigated level pots (control), which were irrigated during the experimental periods at approximately $4 \mathrm{kPa}$. Based on the zinnia plants' water demand and flow rates provided by the spaghetti type emitters (Plasnova, São Paulo, Brazil) used in the drip micro irrigation system (with uniformity coefficient $>0.95$ ), it was possible to establish the following irrigation levels: $46 \%$ (very low), $64 \%$ (low), $75 \%$ (intermediate) and $100 \%$ (well-irrigated) of the water demand of these plants.

The stems were harvested when their petals were fully open and the true central flowers had just begun opening. This occurred from the 27th to the 39th day after transplanting (DAT) in the AW cycle, and from the 37 th to the 62 nd DAT in the WS cycle. In each cycle, i.e., AW and WS, 48 floral stems were harvested and evaluated per treatment (irrigation level), except for the lowest irrigation level (46\%) in the WS cycle where only 46 stems met the minimum length criterion. The stems had to be at least $30 \mathrm{~cm}$ long, which is considered the minimum acceptable length for postharvest evaluations of the zinnia plant (Dole et al., 2009).

\subsection{Standardization of the Material and Postharvest Conditions and Evaluations}

After harvesting, the stems were kept in water for approximately 1 hour to keep them well-hydrated. Following this, the stems were standardized to $30 \mathrm{~cm}$ in length and individually weighed on an analytical balance to obtain their fresh weight. Flower diameter was measured with a graduated ruler and stem diameter was assessed at the median portion of the material using a digital caliper.

The fresh weight, stem diameter and flower diameter of the harvested material were significantly higher in the AW cycle than in the WS cycle. The average values were 4.96, 2.80 and 7.17, respectively in the AW cycle and 3.38, 2.19 and 5.78, respectively, in the WS cycle. Due to standardization, the fresh weight and the stem diameter did not vary among irrigation levels within the same cycle. However, there was a linear growth according to the increase of the irrigation level for the flower diameter.

After standardization, the stems were individually placed in containers on workbenches in the laboratory at room temperature, with approximately $300 \mathrm{~mL}$ of supply water. Daily assessments of fresh weight and water absorption by the stems were performed until their senescence. The stems were weighed on an analytical balance with a precision of $0.2 \mathrm{~g}$ and the variation of fresh weight (VFW) was obtained by the use of equation 1 : 


$$
\operatorname{VFW}(\%)=(100 \times \mathrm{FWt}) / \mathrm{FWi}
$$

in which FWt is the fresh weight of the floral stem on the t-day of the postharvest evaluation $(\mathrm{g})$, and FWi is the initial fresh weight of the floral stem $(\mathrm{g})$.

The water volume in each container was weighed without the stems, and the water was changed daily. Water absorption rate (WAR) was estimated by the volume of water consumed in relation to the initial fresh weight of the stem, using equation 2:

$$
\mathrm{WAR}=((\mathrm{WWi}-\mathrm{WWf}) \times 1000) / \mathrm{FWi}
$$

in which WAR is the water absorption rate ( $\mathrm{mg} \mathrm{g}^{-1}$ of fresh stem weight), WWi is the initial water weight $(\mathrm{g})$, WWf is the final water weight $(\mathrm{g})$, and FWi is the initial fresh weight of the floral stem $(\mathrm{g})$.

\subsection{Proposed Senescence Scale and Longevity of Stems}

There is no known established senescence scale for zinnia plants. Therefore, a classification was developed to assist the producer in the commercialization of the floral stems of this species, and it was based on an adaptation of the senescence scale model of sunflower (Curti et al., 2012). Using this scale, floral stems receive daily scores ranging from 5 to 0 based on their visual appearance and market values represented by the percentage reduction in price, with higher scores representing higher market values.

Some senescence symptoms such as burning of petals, fungal attack or darkening/discoloration of leaves were observed in only a few stems. Thus, scores were assigned based on the main senescence symptoms observed while generating a senescence scale of zinnia (Table 1).

Table 1. Description of the characteristic symptoms of each score of the senescence scale of zinnia ( $c v$. "Red California Giant")

\begin{tabular}{llc}
\hline Score & Sepresentation & Market value (\%) \\
\hline & No visible symptoms & 100 \\
& & \\
Petals starting to discolor or wither \\
and true central flowers closing
\end{tabular}




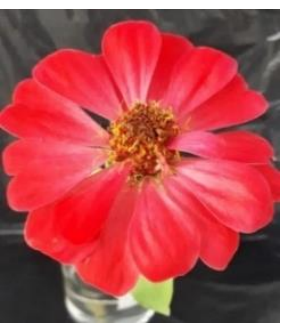

More advanced discoloration or

wilt and total closure of the true

$50-70$ central flowers

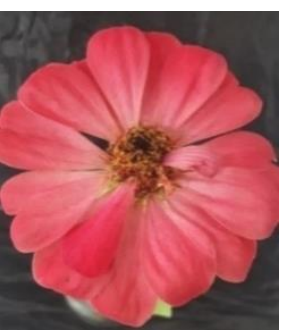

Discoloration or wilting in almost

all of flower's entirety and

darkening of the true central

flowers

Total loss of color and advanced wilt with total darkening of the true

$10-20$ central flowers

Final senescence stage with the fall of petals and/or leaves

From the proposed senescence scale, scores from 5 to 0 were assigned to each stem harvested from the different cycles and irrigation levels. The total and the commercial longevity of zinnia stems, expressed in days of pot life, were also determined. The total longevity represents the period from harvesting to complete senescence i.e., a score of 0 . The commercial longevity represents the period from harvesting to a 50\% drop in the stem's market value (i.e., last day of the assignment of the score 3). This period reflects a time when the stem's commercialization by the producer is no longer profitable.

\subsection{Statistical Analysis}

Statistical analyses for floral stem fresh weight and water absorption were also performed for each cycle (until 26 days after harvest for the AW cycle and 20 days after harvest for the WS cycle). The split plots scheme with randomized complete blocks design was adopted, in which the irrigation levels factor was applied to the whole plots and the days after harvest factor was applied to the sub-plots. 


\section{Macrothink Institute $^{\mathrm{TM}}$}

To ascertain the basic assumptions of the analysis of variance (ANOVA), the normality was evaluated using Shapiro-Wilk's test $(\mathrm{p} \leq 0.05)$ and the homogeneity of the residues were verified using Bartlett's test $(\mathrm{p} \leq 0.05)$. As a result, the data referring to the average duration of score 1 of the senescence scale were transformed into $\sqrt{\mathrm{x}}$. When the null hypothesis was rejected during ANOVA using the $F$ test $(\mathrm{p} \leq 0.05)$, the regression analysis was carried out using the Student's t test to verify the fit of the linear and the quadratic models to the total longevity and the commercial longevity data in each irrigation level. The model with the lowest level of significance ( $\mathrm{p}$-value) and the highest coefficient of determination was then selected. For the average duration of the scores of the senescence scale, the Scott-Knott's test was performed $(\mathrm{p} \leq 0.05)$. All the analyses were performed using the computer programs $\mathrm{R}$ (3.6.0) (R Core Team, 2018) and Sisvar (5.6) (Ferreira, 2011).

\section{Results and Discussion}

\subsection{Variations in the Fresh Weight and Water Absorption Rate}

The variation in the stems' fresh weight followed a similar pattern for all irrigation levels, both in the AW cycle (Figure 1A) and in the WS cycle (Figure 1B), in the average period of total longevity of stems. For the WS cycle, there were no statistically significant differences among irrigation levels for any of the studied variables ( $p>0.05, F$ test).

For the AW cycle there was a difference among treatments for both the fresh weight and water absorption rate $(\mathrm{p}<0.05, \mathrm{~F}$ test). The total longevity of stems was influenced by the irrigation levels in the period from 20 to 22 days after harvest. The treatments $46 \%$ and $100 \%$ were equally superior to the $64 \%$ and $75 \%$, which did not differ from each other according to the Scott-Knott's test at 5\% probability level (Figure 1A). 

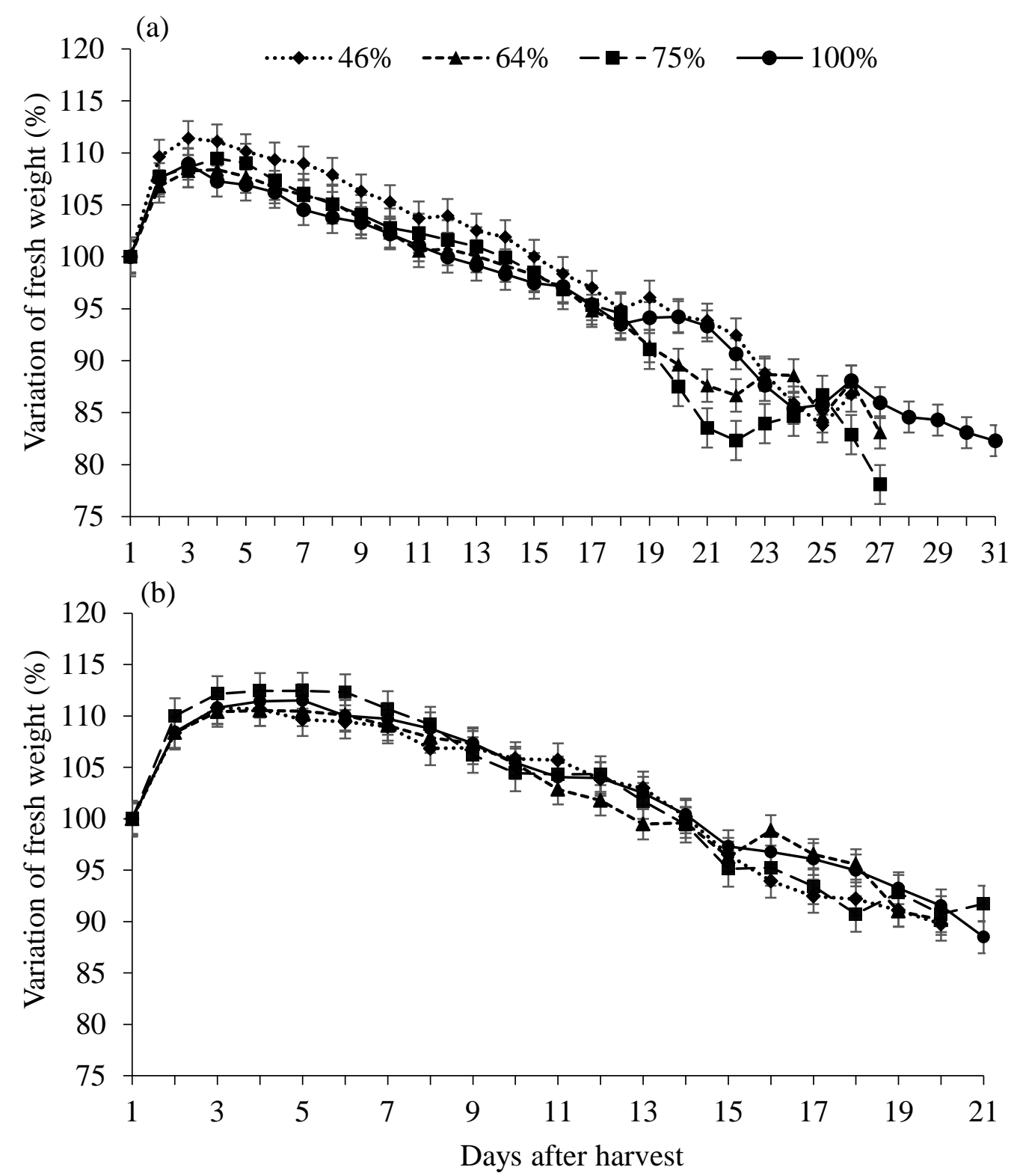

Figure 1. Variation in fresh weight $(\%)$ in the postharvest period of floral stems of zinnia, $c v$. "Red California Giant", obtained from plants cultivated under different irrigation levels in the autumn-winter (a) and winter-spring (b) cycles

In the AW cycle, the fresh weight tended to increase by $11 \%, 8 \%, 9 \%$ and $9 \%$ in the stems obtained from the irrigation levels of $46 \%, 64 \%, 75 \%$ and $100 \%$, respectively until the 3rd day of storage (Figure 1A). This was $11 \%, 11 \%, 12 \%$ and $11 \%$ for the same irrigation levels, respectively, for the WS cycle until the 4th day of evaluation (Figure 1B). From the 5 th day, the floral stems tended to lose fresh weight. In the AW cycle, the fresh weight was lower than the initial weight from the 16th, 14th, 14th and 12th days after harvest for the stems of the levels of $46 \%, 64 \%, 75 \%$ and $100 \%$, respectively. In contrast, in the WS cycle this happened from the 15th, 13th, 14th and 15th days after harvest for the same irrigation levels, respectively.

The stems lost, on average, $17 \%$ and $10 \%$ of fresh weight from the first day of evaluation until the end of their longevity period in the AW and WS cycles, respectively (Figure 1). In 


\section{A. Macrothink}

this study, there was no treatment done on the floral stems. This implies that weight loss for the zinnia species is normal due to the decrease in endogenous sucrose levels. It has been shown that neither the use of biocidal preservatives nor pulsing treatment with sucrose has an effect on the longevity of zinnia flowers (Carneiro et al., 2002; Pêgo et al., 2020). Additionally, higher plant respiratory rates in less favorable conditions can also lead to the loss of fresh weight.

The water absorption rate followed a similar pattern as was shown by the variation in fresh weight in the different irrigation levels. However, the variation between cycles was more pronounced when assessing the average period of total longevity of the stems (Figure 2).
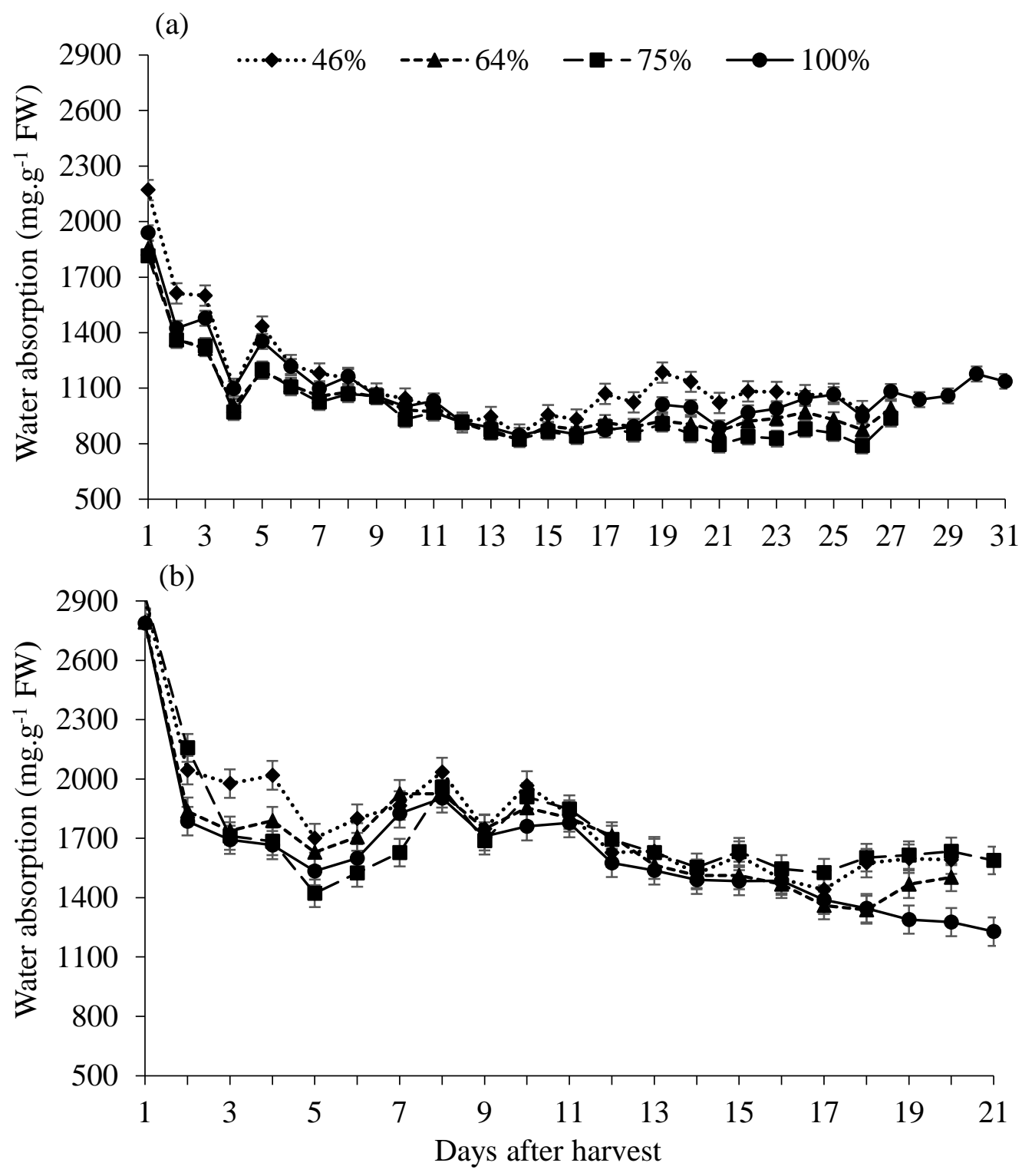

Figure 2. Variation in the water absorption rate $\left(\mathrm{mg} \mathrm{g}^{-1}\right.$ of fresh weight of stem) in the postharvest period of floral stems of zinnia, $c v$. "Red California Giant", obtained from plants cultivated under different irrigation levels in the autumn-winter (a) and winter-spring (b) cycles 
For the AW cycle, the water absorption was significantly influenced by the irrigation levels for only a few days during the postharvest period ( $\mathrm{p}<0.05, \mathrm{~F}$ test). The $46 \%$ treatment was superior to the others on days 1,2, 19 and 20 after harvest. At 3, 5 and 25 days after harvest, this treatment was similar to the $100 \%$ treatment, and superior to the $64 \%$ and $75 \%$ treatments, which did not differ from each other by the Scott-Knott's test at $5 \%$ probability level (Figure 2A).

In absolute terms, in both cultivation cycles, the day after harvesting (the first day of the evaluation of water absorption) was the one in which the water absorption rates were the highest regardless of the irrigation level. In the AW cycle, the rate of the first day was, on average, $1950 \mathrm{mg} \mathrm{g}^{-1}$ of fresh stem weight (Figure 2A), whereas in the WS cycle this was, on average, $2850 \mathrm{mg} \mathrm{g}^{-1}$ of fresh stem weight (Figure 2B). The WS rate was approximately $32 \%$ higher than the AW cycle. After the first day, there was a decrease in the water absorption at all irrigation levels and in both cultivation cycles. By the last day of evaluation, there was a $48 \%$ reduction in the water absorption rate in both cultivation cycles based on the rates on the first day of evaluation. This indicates that water absorption by the stems is higher at the beginning of storage.

The initial water absorption in the WS cycle (Figure 2B) was higher than in the AW cycle (Figure 2A) possibly because WS were not so favorable to the development of zinnia, leading to the production of lower quality flowers, or the suboptimal hydration status of the plants at the time of harvest. Although the water absorption sporadically increased on some days, this was followed by new drops. This variation could be explained by variations in the temperature in the stems' storage location that influenced the evaporation of water from the containers and the transpiration of the stems.

There was a direct correlation between the variation in fresh weight and the water absorption by the stems. The initial high water absorption rate (Figure 2) promoted an increase in the fresh weight of the stems on the first days of the evaluation (Figure 1). Besides this, an increase in fresh weight was also attributed to the opening of the true central flowers. This is because the time of harvesting was marked by the beginning of the opening of the true central flowers, a process that was only completed on the first days of storage. Zinnia stems, $c v$. "Double Choice Mixed", which received cuts at the base, showed a slight increase in the fresh weight until 44 hours after harvesting. However, this increase did not differ from those that did not have the base cut (Carneiro et al., 2002).

\subsection{Longevity of Stems}

The daily assignment of the senescence scale scores (Table 1) allowed us to observe the variation in the quality of the stems in the postharvest period. In the AW cycle, the total observation period was $42,42,41$ and 44 days for the $46 \%, 64 \%, 75 \%$ and $100 \%$ of the water requirements, respectively (i.e., irrigation level) (Figure 3). Whereas in the WS, this was considerably shorter i.e., 31, 31, 33 and 33 days for the $46 \%, 64 \%, 75 \%$ and $100 \%$ of the water requirements (Figure 4). Thus, it can be concluded that the analyzed stems of the AW cultivation lasted longer in the postharvest period than those of the WS cycle. 
(a)
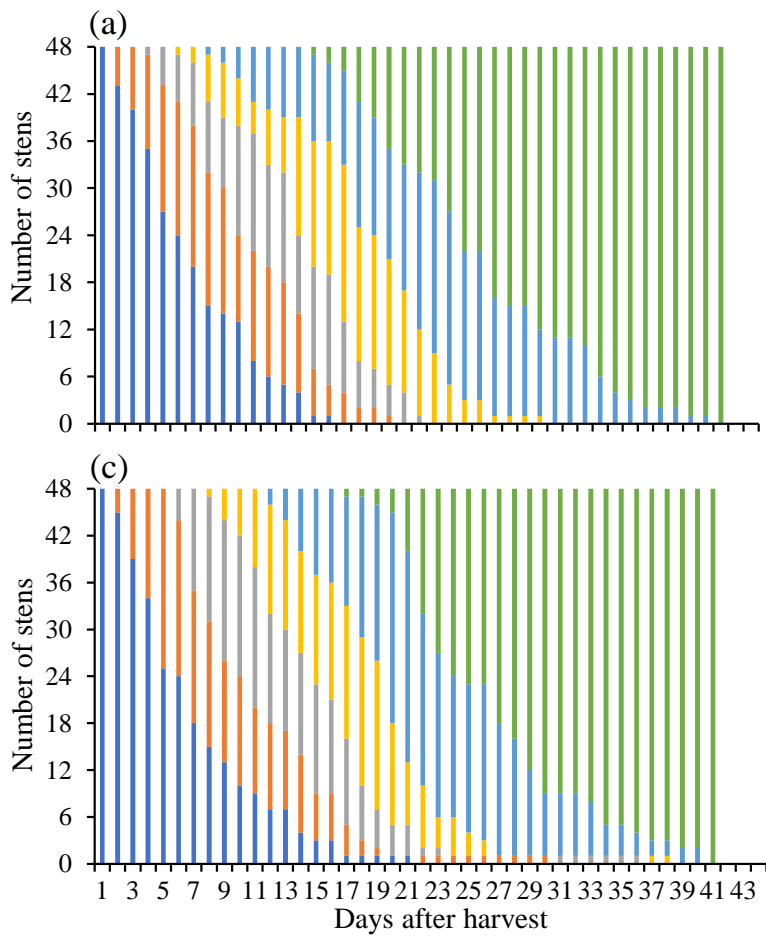

(b)

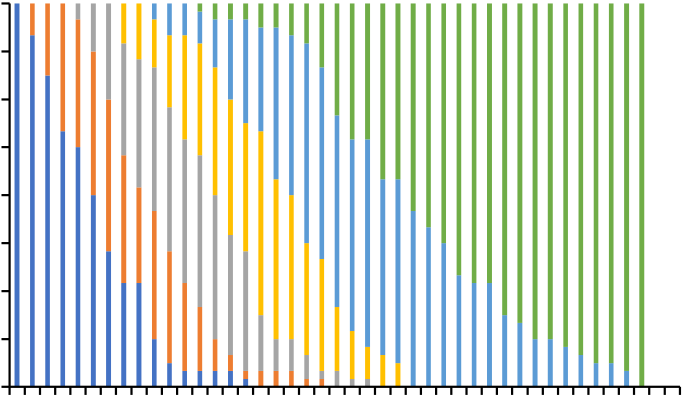

(d)

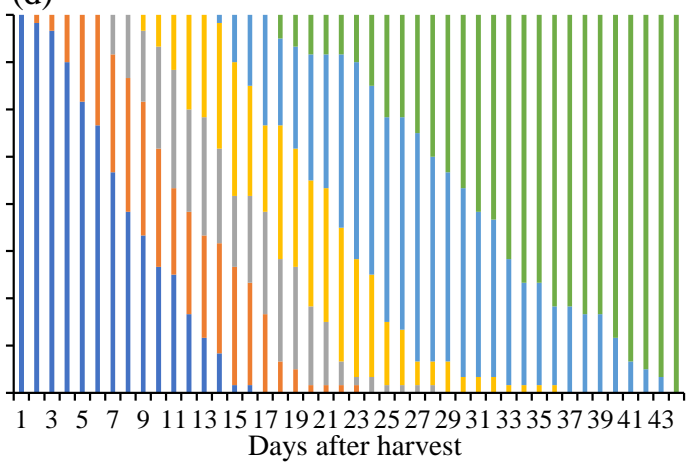

Figure 3. Variation of the scores attributed to the stems of zinnia, $c v$. "Red California Giant", obtained from the autumn-winter cycle for the different irrigation levels applied: $46 \%$ (a), $64 \%$ (b), $75 \%$ (c) and $100 \%$ (d)

As regards the duration in which the plant had the best quality and greatest commercial value (i.e., a score of 5), in the AW cycle, this was 16, 16, 21 and 16 days for the irrigation levels of $46 \%, 64 \%, 75 \%$ and $100 \%$ (Figure 3). In the WS cycle this occurred on the 15th, 18th, 16th and 17 th days of assessment, for the levels of $46 \%, 64 \%, 75 \%$ and $100 \%$, respectively (Figure 4). From the mentioned day onwards, all stems began showing a senescence symptom which marked the end of the assignment of the score 5 to each stem.

The disposal of the stems, marked by the assignment of the score 0 (when the senescence process was completed), started on the 15th, 13th, 17th and 18th days after the harvest of the stems from the plants grown with $46 \%, 64 \%, 75 \%$ and $100 \%$, respectively, of water replacement in the AW cycle (Figure 3). In the WS cycle, the disposal started on the 6th, 8th, 10th and 10th days after the harvest of the stems obtained from the plants submitted to the same irrigation levels, respectively (Figure 4). Thus, the senescence process was slower in the AW cycle when compared to the WS cycle. 
$\square$ Score $5 \quad$ Score $4 \quad \square$ Score $3 \quad$ Score $2 \square$ Score $1 \quad$ Score 0

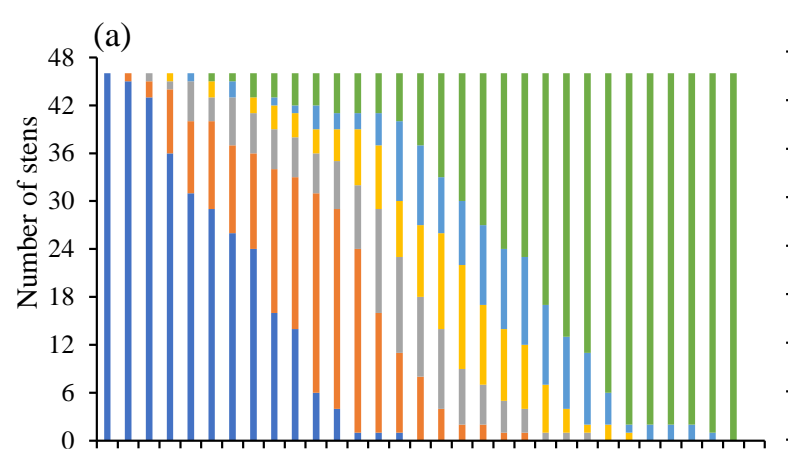

(b)
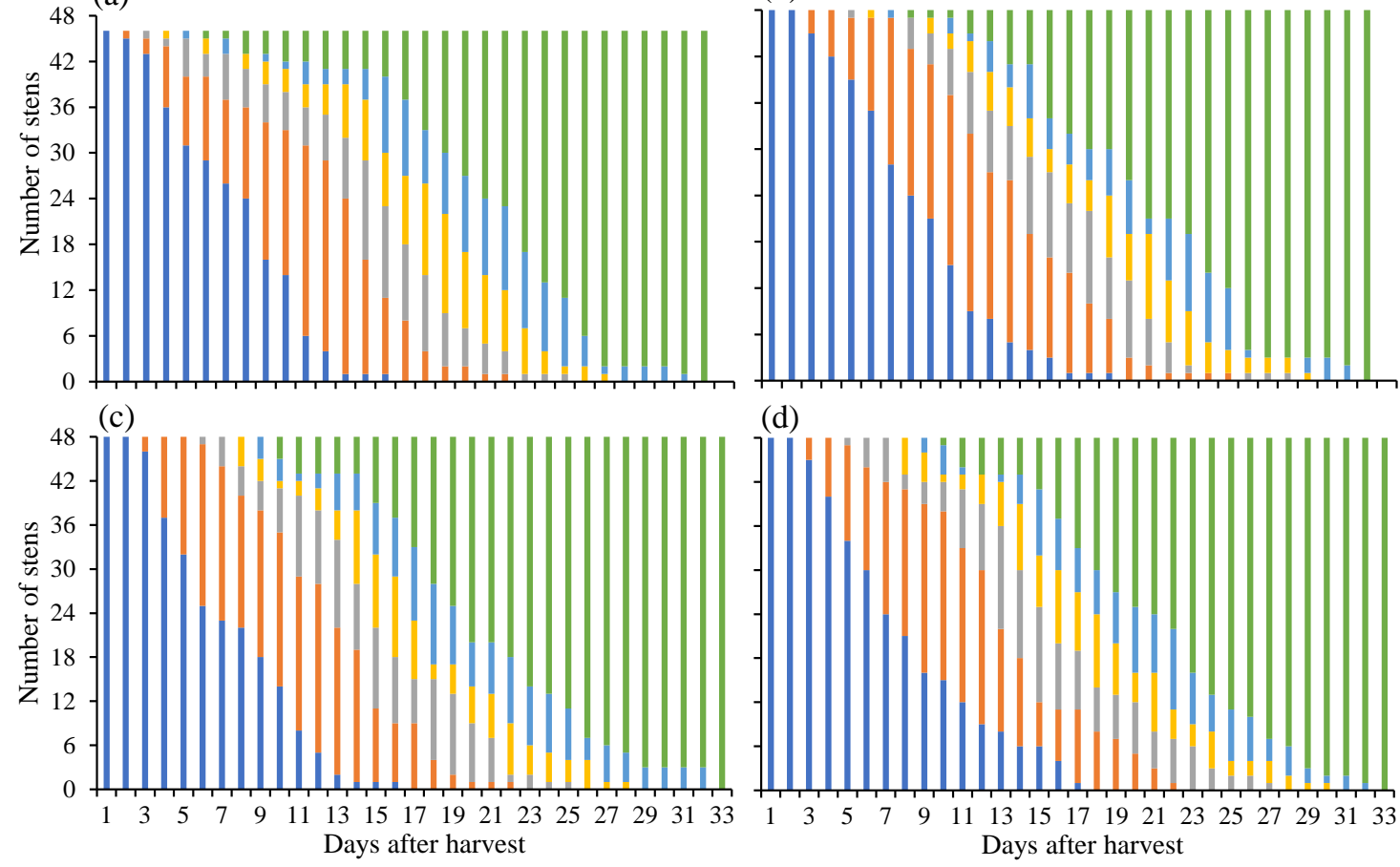

(d)

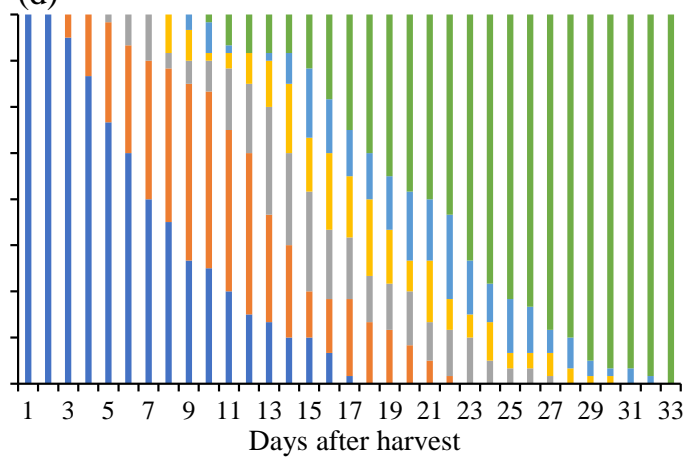

Figure 4. Variation of the scores attributed to the stems of zinnia, $c v$. "Red California Giant", obtained from the winter-spring cycle for the different irrigation levels applied: $46 \%$ (a), $64 \%$ (b), $75 \%$ (c) and $100 \%$ (d)

The reduction in the water absorption rate and the loss of fresh weight by wilting intensifies the senescence process and thus the assignment of lower scores on the senescence scale. Therefore, the variation in stem fresh weight, which showed a greater reduction from the 18th and 15th days of evaluation in the AW (Figure 1A) and WS (Figure 1B) cycles, intensified the disposal of stems and the decrease in the floral quality observed (Figures 3 and 4).

The duration of each score varied from one cycle to the other. In the AW cycle, the scores 5 and 1 lasted the longest (Figure 5A). However, those scores were 5 and 4 in the WS cycle (Figure 5B). 

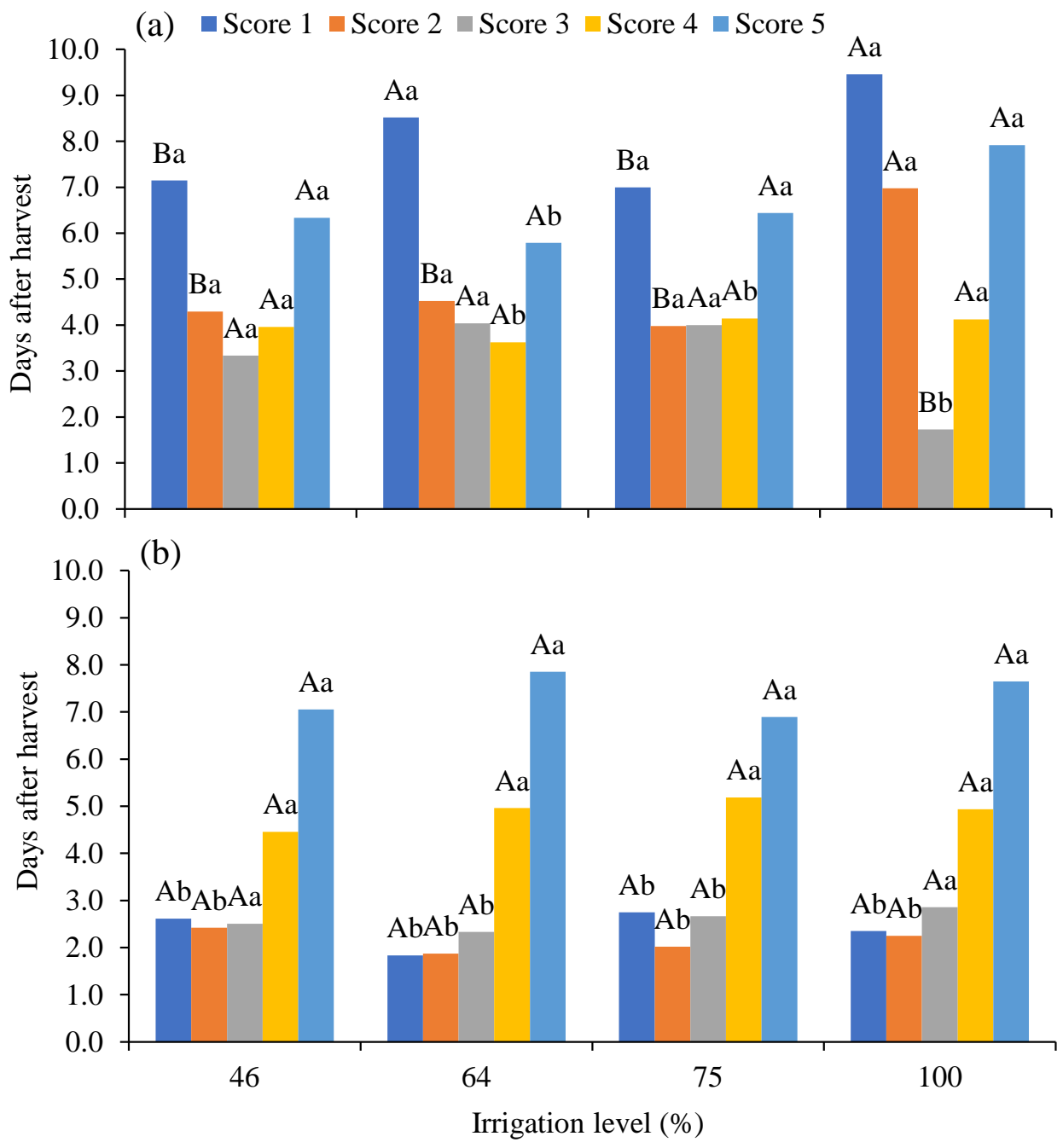

Figure 5. Average duration of the scores (days) of the senescence scale of floral stems of zinnia, $c v$. "Red California Giant", grown under different irrigation levels in the autumn-winter (a) and winter-spring (b) cycles. Mean values followed by the same capital letters do not differ among irrigation levels and the same lowercase letters do not differ between cultivation cycles by the Scott-Knott's test ( $p>0.05)$

The duration in which the flowers were at score 5 did not vary among the different irrigation levels within each cycle. The score 5 lasted, approximately, 7 days, on average, in both cultivation cycles, which characterizes a positive result, as it is the score that represents the highest quality of stems, resulting in a large window to commercialize the stems with $100 \%$ of their commercial value. When comparing the AW to the WS cycle, only the duration of score 5 for the $64 \%$ irrigation level of the AW cycle was shorter than the WS one; nevertheless, it lasted more than 5 days.

The duration in which the flowers were at scores 2 and 1 were significantly shorter in the WS cycle than in the AW cycle (Figure 5). This may be due to the intrinsic quality of the material evaluated in each cycle. The thinner stems with lower fresh weight and smaller flower diameter from the WS cycle tended to exhaust their sugars more rapidly and complete the senescence process faster than those from the AW cycle. The characteristics mentioned above, 
including the flower diameter, are important flowers classifying characteristics used to determine the aesthetic value and therefore, the market value of flowers. The flower diameter is an important characteristic in the classification of the flowers of the Asteraceae family, such as zinnia.

The total longevity of stems (scores 5 to 0 of the senescence scale) showed a significant difference between the cultivation cycles (Figure 6A), and in the AW cycle it was, on average, $23 \%$ higher than in the WS cycle.
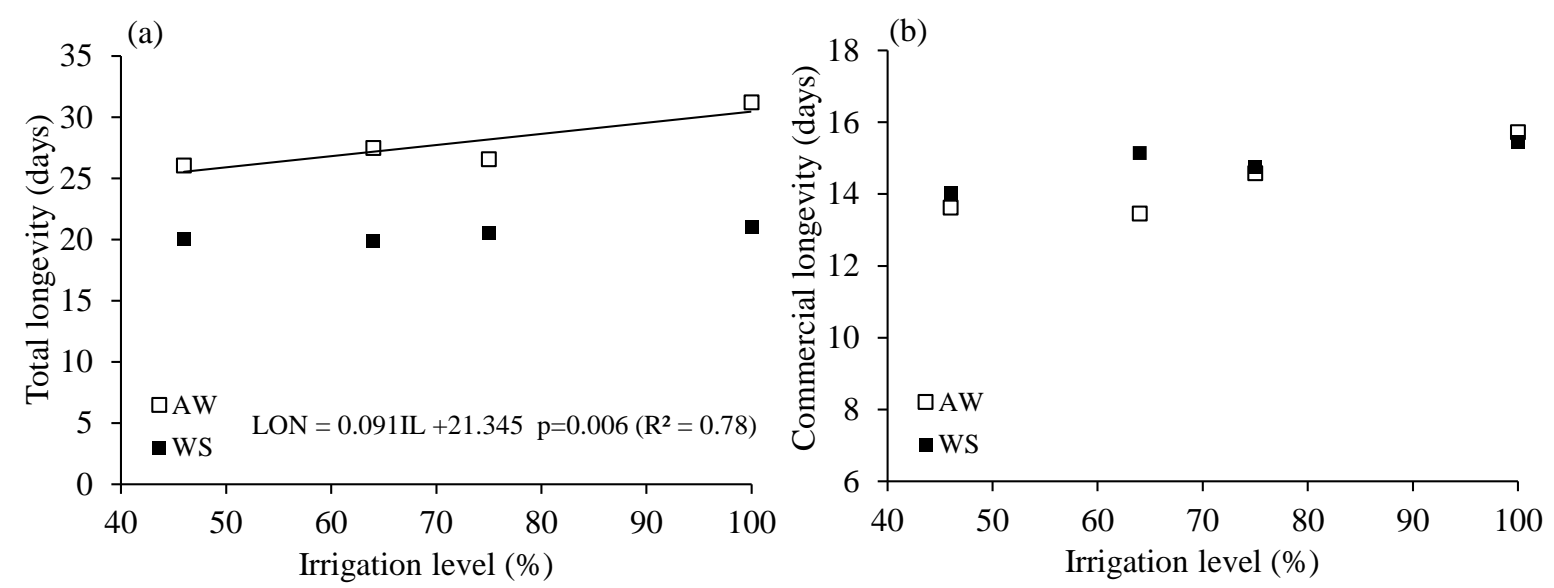

Figure 6. Total (a) and commercial (b) longevity (days) of the floral stems of zinnia, $c v$. "Red California Giant", grown under different irrigation levels in the autumn-winter and winter-spring cycles

The irrigation levels only had a significant impact in the AW cycle, with a linear growth trend that varied with an increase in the water applied. The linear growth trend at $100 \%$ irrigation level was approximately $16 \%$ higher than the lowest level $(46 \%)$. The average commercial longevity (from scores 5 to 3 of the senescence scale) of approximately 14.6 days did not vary due to the growing seasons and irrigation levels used (Figure 6B).

The establishment of a standardized methodology to assess cut flowers' senescence permitted an objective assessment of their commercialization and longevity (Curti et al., 2012). Thus, by using the senescence scale proposed for zinnia (Table 1), it was possible to determine a similar commercial longevity for all irrigation levels and cycles (Figure 6B), even though the senescence process was completed faster in the WS cycle (Figure 4) than in the AW one (Figure 3). This would not have been observed in the absence of this senescence scale. Besides this, the proposed methodology could also be applied to the classification and sales stages of these products in the wholesale and retail market to commercialize zinnia as a cut flower.

The quality of the stems grown in the WS cycle rapidly depreciated after the end of the assignment of the score 3 (Figure 5B), that represents the commercial longevity. This effectively reduced their total longevity when compared to those from the AW cycle (Figure $6 \mathrm{~A})$. On average, the stems evaluated in the AW cycle took 13 days to go from score 2 to 0 of the senescence scale (Figure 5A), while this was 6 days in the WS cycle (Figure 5B). 
However, this duration is not as important as the commercial longevity, since the stems are hardly commercialized when they lose more than $50 \%$ of their commercial value.

The longevity of flowers, which is related to its species-specific characteristics and its cultivars, is determined by both pre- and postharvest factors (Nowak \& Rudnicki, 1990). The use of preservative solutions to prolong the longevity of cut flowers is now widely developed and is a recurrent practice in countries in which floriculture is an important income-generating sector (Dias-Tagliacozzo et al., 2003). However, preservative products may not be beneficial for all species (Schmitt et al., 2014), since zinnia stems, $c v$. "Double Choice Mixed", treated with different solutions with sucrose and distilled water had a longevity of approximately 8 days (Carneiro et al., 2002). Thus, the commercial longevity of zinnia, $c v$. "Red California Giant", was satisfactory even without the use of a preservative product since it exceeded 14 days, on average (Figure 6B). However, the use of these products to extend its longevity could be evaluated in future studies.

The variation in fresh weight and the water absorption rate are directly associated with the longevity of the stems. As the water absorption by the stems reduces, their fresh weight also tends to decrease, promoting their senescence. This is also mentioned by Schmitt et al. (2014), who state that one of the factors that determine the longevity of flowers is the amount of water transported by the stem. Thus, the senescence and the withering of cut flowers may be associated with the reduced water absorption by the stems (Carneiro et al., 2002). It is important to note that as our stems were not treated with floral preservatives, the loss of longevity could also be related to the depletion of sugars and other sources of energy in the flowers, which is common to all ornamental species in the postharvest period.

Nomura et al. (2014) observed that the loss of fresh weight in anthurium "Apalai" (as reflected in the drastic drop in the score index) reduced its commercial durability and the total longevity of its stems. Durigan et al. (2013) also associated the accentuated symptoms of senescence to the decline in the variation in fresh weight in gerbera "Suzanne".

It can therefore be concluded that a scale based on the predominant senescence symptoms permits the determination of the postharvest longevity of the floral stems of zinnia, $c v$. "Red California Giant", and assists in its commercialization by the producers.

Both cultivation cycles, autumn-winter and winter-spring, allowed satisfactory postharvest results, as measured by commercial longevity and the duration of the stems in the score 5 of the senescence scale, which could be considered the most important evaluated parameters.

The irrigation levels $(46 \%, 64 \%, 75 \%$ and $100 \%$ of the species' water necessity) did not influence the postharvest results of cut zinnia "Red California Giant" flowers.

\section{References}

Almeida, E. F. A., Lima, L. C. O., Silva, F. C., Resende, M. L., Nogueira, D. A., \& Paiva, R. (2009). Diferentes conservantes comerciais e condições de armazenamento na pós-colheita de rosas. Revista Ceres, 56(2), 193-198.

Carneiro, T. F., Finger, F. L., Santos, V. R., Neves, L. L. M., \& Barbosa, J. G. (2002). 
Influência da sacarose e do corte da base da haste na longevidade de inflorescências de Zinnia elegans. Pesquisa Agropecuária Brasileira, 37(8), 1065-1070. https://doi.org/10.1590/S0100-204X2002000800003

Cassaniti, C, Romano, D., Hop, M. E. C. M., \& Flowers, T. J. (2013). Growing floricultural crops with brackish water. Environmental and Experimental Botany, 92, 165-175. https://doi.org/10.1016/j.envexpbot.2012.08.006

Curti, G. L., Martin, T. N., Ferronato, M. D. L., \& Benin, G. (2012). Girassol ornamental: caracterização, pós-colheita e escala de senescência. Revista de Ciências Agrárias, 35(1), 240-250.

Davarynejad, E., Tehranifar, A., Ghayoor, Z., \& Davarynejad, G. H. (2008). Effect of Different Pre-Harvest Conditions on the Postharvest Keeping Quality of Cut Gerbera. Acta Horticulturae, 804, 205-208. https://doi.org/10.17660/ActaHortic.2008.804.26

Dias-Tagliacozzo, G. M., Zullo, M. A., \& De Castro, C. E. F. (2003). Caracterização física e conservação pós-colheita de alpínia. Ornamental Horticulture, 9(1), 17-23. https://doi.org/10.14295/rbho.v9i1.161

Dole, J. M., Viloria, Z., Fanelli, F. L., \& Fonteno, W. (2009). Postharvest evaluation of cut dahlia, linaria, lupine, poppy, rudbeckia, trachelium, and zinnia. HortTechnology, 19(3), 593-600. https://doi.org/10.21273/HORTSCI.19.3.593

Durigan, M. F. B., Mattiuz, B. H., Rodrigues, T. D. J. D., \& Mattiuz, C. F. M. (2013). Uso de soluções de manutenção contendo ácido cítrico, cloro ou 8-HQC na conservação pós-colheita de flores cortadas de gérbera 'Suzanne'. Ornamental Horticulture, 19(2), 107-116. https://doi.org/10.14295/rbho.v19i2.352

Ebrahimzadeh, A., Jiménez, S., Da Silva, J. T., Satoh, S., \& Lao, M. T. (2008). Post-harvest physiology of cut carnation flowers. Fresh Produce, 2(2), 56-71.

Farias, M. F. D., Saad, J. C. C., Carnietto, M., \& Laschi, D. (2009). Efeito de tensões de água no solo na qualidade e longevidade floral do crisântemo de corte. Pesquisa Aplicada \& Agrotecnologia, 2(1), 135-140.

Ferreira, D. F. (2011). Sisvar: a computer statistical analysis system. Ciência $e$ agrotecnologia, 35(6), 1039-1042. https://doi.org/10.1590/S1413-70542011000600001

Franzen, F. L., Richards, N. S. P. S., Oliveira, M. S. R., Backes, F. A. A. L., Menegaes, J. F., \& Zago, A. P. (2016). Caracterização e qualidade nutricional de pétalas de flores ornamentais. Acta Iguazu, 5(3), 58-70.

Heidari, Z., Nazarideljou, M. J., Danesh, Y. R., \& Khezrinejad, N. (2016). Morphophysiological and biochemical responses of Zinnia elegans to different irrigation regimes in symbiosis with Glomus mosseae. International Journal of Horticultural Science and Technology, 3(1), 19-32. https://doi.org/10.22059/IJHST.2016.58158.

Junqueira, A. H., \& Peetz, M. S. (2014). The productive sector of flowers and ornamental 
plants of Brazil, in the period from 2008 to 2013: updates, balance sheets and prospects. Ornamental Horticulture, 20(2), 115-120. https://doi.org/10.14295/rbho.v20i2.727

Lima, J. D., \& Ferraz, M. V. (2008). Cuidados na colheita e na pós-colheita das flores tropicais. Ornamental Horticulture, 14(1), 29-34. https://doi.org/10.14295/rbho.v14i1.228

Loges, V., Teixeira, M. D. C. F., Castro, A. D., \& Costa, A. D. (2005). Colheita, pós-colheita e embalagem de flores tropicais em Pernambuco. Horticultura Brasileira, 23(3), 699-702. https://doi.org/10.1590/S0102-05362005000300001

Medici, L. O., Rocha, H. S. D., Carvalho, D. F., Pimentel, C., \& Azevedo, R. A. (2010). Automatic controller to water plants. Scientia Agricola, 67(6), 727-730.

https://doi.org/10.1590/S0103-90162010000600016

Nomura, E. S., Fuzitani, E. J., Junior, D., \& Rafael, E. (2014). Soluções de condicionamento em pós-colheita de inflorescências de antúrio. Revista Ceres, 61(2), 219-225.

https://doi.org/10.1590/S0034-737X2014000200009

Nowak, J., \& Rudnicki, R. M. (1990). Postharvest handling and storage of cut flowers, florist greens and potted plant. Portland, Timber Press, p. 210.

https://doi.org/10.1007/978-94-009-0425-5

Pêgo, R. G., Antunes, L. F. S., \& Silva, A. R. C. (2019). Vigor of zinnia seedlings produced in alternative substrate in trays with different cell size. Ornamental Horticulture, 25(4), 417-424. https://doi.org/10.1590/2447-536x.v25i4.2049

Pêgo, R. G., Marcos, A, \& Ferreira, T. S. (2020) Conservantes naturais na pós-colheita de flores de zinia. Cadernos de Agroecologia, 15(2), 1-5.

R Core Team (2018). R: A language and environment for statistical computing. R Foundation for Statistical Computing, Vienna, Austria. https://www.R-project.org/

Sardoei, A. S., Fahraji, S. S., \& Ghasemi, H. (2014). Effects of different growing media on growth and flowering of zinnia (Zinnia elegans). International Journal of Advanced Biological and Biomedical Research, 2(6), 1894-1899.

Schmitt, F., Milani, M., Duarte, V., Schafer, G., \& Bender, R. J. (2014). Conservantes florais comerciais nas soluções de manutenção de hastes florais de gérbera de corte. Ciência Rural, 44(12), 2124-2128. https://doi.org/10.1590/0103-8478cr20120750

\section{Copyright Disclaimer}

Copyright for this article is retained by the author(s), with first publication rights granted to the journal.

This is an open-access article distributed under the terms and conditions of the Creative Commons Attribution license (http://creativecommons.org/licenses/by/4.0/). 